\title{
Eğitimin Ekonomik Büyüme Üzerindeki Etkileri: AB Ülkeleri İçin Panel Veri Analizi
}

\author{
Dilek KUTLUAY SAHIN \\ Çankırl Karatekin Üniversitesi, İIBF, İktisat Bölümü, \\ dilekkutluay@karatekin.edu.tr, ORCID: 0000-0002-0118-4329
}

Öz

Ekonomik büyümeyi belirleyen çok sayıda değişken vardır. Bu değişkenlerden biri de eğitimdir. Bu kapsamda çalışmanın amacı Avrupa Birliği ülkelerinde ekonomik büyüme ve eğitim arasındaki ilişkiyi tespit etmektir. 2002-2018 dönemine ait ilköğretim, ortaöğretim ve yükseköğretim diplomasına sahip olan işgücü verilerinin yıllık olarak kullanıldığı bu çalışmada öncelikle konu ile ilgili literatüre yer verilmiştir. Sonrasında Avrupa Birliği ülkelerinde eğitimin ekonomik büyüme üzerindeki etkisi ilköğretim, ortaöğretim ve yükseköğretim diplomasına sahip olan işgücü verileri kullanılarak, panel veri yöntemi ile analiz edilmiştir. Çalışmada kullanılan veriler Eurostat ve Dünya Bankası veri kaynaklarından elde edilmiştir. Çalışma sonucunda elde edilen analiz bulgularına göre bütün öğretim düzeylerinde çalışanların ekonomik büyümeyi arttırdığı sonucuna ulaşılmıştır. Dolayısıyla ekonomik büyümeye önem veren ülkeler eğitime fazla kaynak ayırmalidirlar.

Anahtar Kelimeler: Eğitim, Ekonomik Büyüme, Panel Veri Analizi

Jel Sinıflandırma Kodları: C23, I21, O47

\section{The Impacts of Education on Economic Growth: Panel Data Analysis for EU Countries ${ }^{1}$}

\begin{abstract}
Many variables determine economic growth. One of these variables is education. In this context, the study aims to reveal the relationship between education and economic growth in European Union countries. In this study, where the workforce data of the period of 2002-2018 with primary education, secondary education and higher education diplomas are used annually, firstly, the relevant literature is included. Then, the impact of education on economic growth in EU countries is analyzed using the panel data method, using labor data with primary, secondary, and higher education diplomas. The data used in the study were obtained from Eurostat and the World Bank database. According to the analysis findings obtained as a result of the study, it has been concluded that employees at all levels of education increase economic growth. Therefore, countries that attach importance to economic growth should allocate more resources to education.
\end{abstract}

Key Words: Education, Economic Growth, Panel Data Analysis

Jel Classification Codes : C23, I21, O47

1 Extended abstract is presented at the end of the article.

Geliş Tarihi (Received): 09.04.2020 Kabul Edilme Tarihi (Accepted): 16.12.2020

Atıfta bulunmak için/Cite this paper:

Kutluay Şahin, D. (2020). Eğitimin ekonomik büyüme üzerindeki etkileri: AB ülkeleri için panel veri analizi, Çankırl Karatekin Üniversitesi IIBBF Dergisi, 10 (2), 657-672. Doi: 10.18074/ckuiibfd.717393 


\section{Giriş}

Dünyada yaşanan değişim ve gelişim sürecinde kalkınmanın temelinin bilgi üretimi olduğu fark edilmiştir. Bilgi toplumunun en önemli öğesi olan bilgiye yatırım yapmayı başarabilen ülkeler, sürdürülebilir bir ekonomik büyümeyi yakalamışlardır. Eğitimin nitelikli işgücünün ülke ekonomisine yaptığı katkının arttırılmasında önemli bir rolü vardır. Eğitim beşeri sermayenin en temel faktörlerinden biridir. Eğitimin emek faktörünün verimliliğini arttırarak ekonomik büyümeyi pozitif yönde etkilediği söylenebilir.

Beşeri sermaye kavramı Adam Smith, J.Stuart Mill ve Alfred Marshall gibi klasik iktisatçılara uzanmakla birlikte 1960'l1 y1llarda Schultz (1961), Denison (1962) ve Becker (1964) gibi iktisatçılar Smith'in görüşlerinden yola çıkarak ilk defa formel olarak ortaya konulan beşeri sermaye teorisini geliştirmişlerdir. Denison (1962), analiz sonucunda işgücünün eğitim düzeyindeki artışın ekonomik büyümeyi arttırdığını ortaya koymuştur. Harbison (1971), eğitimin ekonomik büyümede temel bir etken olduğunu vurgulamıştır.

Solow (1956), makalesi ekonomik büyüme kavramının temellerini ortaya koyması açısından önemlidir. Solow modeline göre ekonomik büyümeyi, daha çok yatırım ve işgücü artış hızı belirlemektedir. Ayrıca modele göre teknolojik gelişme de büyümeyi etkileyen önemli bir faktördür. Mankiw, Romer ve Weil (1992), Solow büyüme modeline beşeri sermaye değişkenini ekleyerek beşeri sermayenin ekonomik büyüme üzerinde önemli bir rolü olduğunu vurgulamışlardır. Ayrıca Romer (1990), beşeri sermayenin ekonomik büyümenin önemli belirleyicilerinden biri olduğunu vurgulamıştır.

Günümüzde eğitimin ekonomik büyümeyi önemli düzeyde etkilediği kabul edilmektedir. İktisat teorisinde ekonomik büyüme üzerinde eğitimin etkisini anlayabilmek için yapılan çalışmalar geniş bir literatür oluşturmaktadır.

İçsel büyüme teorisi ile beşeri sermaye faktörü, büyüme literatürüne eklenmiştir. Dolayısıyla beşeri sermaye, ekonomik büyüme için gerekli bir unsur olup bu da insana yatırımı zorunlu hale getirmektedir. Eğitim de insana yapılacak yatırımın unsurlarından biridir ve beşeri sermayenin geliştirilmesindeki en temel etkendir (Afşar, 2009, s. 86). Eğitimli işgücü kaynağı içsel büyümenin temel öğelerinden biridir. Eğitim olanaklarının artması işgücü verimliliğini arttırmaktadır (Yardımcıoğlu, Gürdal ve Altundemir, 2014, s. 1).

Ülke ekonomilerinin kalkınmasında eğitimin rolü büyüktür. Eğitim hem kalkınmada gerekli olan nitelikli işgücünün teminine imkân sağlamakta hem de ülkelerin üretim tekniklerinin geliştirilmesine ve üretim aşamasında kullanılmasına firsat sunmaktadır. Eğitim düzeyi yükseldikçe işgücü verimliliği artmakta; ülkelerin verimliliği bu durumdan pozitif yönlü etkilenmektedir. Bu durum ülkelerin dışa açılmalarını daha kolay hale getirmektedir. Gelişmiş ve 
gelişmekte olan piyasa ekonomileri performans açısından değerlendirildiğinde aradaki farklılığın temel sebeplerinden birinin eğitim düzeylerindeki farklılık olduğu anlaşılmıştır (Çalışkan, Karabacak ve Meçik, 2013, s. 30). Bir ülke ekonomisinin gelişmiş olması o ülke bireylerinin iyi bir eğitim almalarına ve bu eğitim neticesinde kazandıkları bilgi ve beceri ile ekonomik büyümeye katkı yapmalarına bağlıdır. Lucas (1988, s. 3) çalışmasında eğitimin beşeri sermayenin en önemli öğesi olduğunu ve sürdürülebilir ekonomik kalkınmanın beşeri sermayenin bir neticesi olduğunu belirtmiştir.

Çalışma; kullanılan veriler, analiz edilen yıl aralığı ve ülke örnekleri açısından diğer çalışmalardan farklıdır. $\mathrm{Bu}$ farklılık çalışmanın özgün değerini oluşturmaktadır. Çalışmanın amacı Avrupa Birliği (AB)'ndeki ekonomik büyüme ve eğitim arasındaki ilişkiyi araştırmaktır. $\mathrm{Bu}$ amaç doğrultusunda çalışmada öncelikle literatürde ekonomik büyüme ve eğitim arasındaki ilişkiyi ampirik ve teorik düzeyde araştıran çalışmalara yer verilmiştir. Sonraki aşamalarda veri kaynakları, yöntem hakkında bilgi verildikten sonra eğitim ile ekonomik büyüme arasındaki ilişki, 2002-2018 dönemi için Avrupa Birliği ülke örnekleri bağlamında panel veri analizi uygulanarak incelenmiştir. Son aşama olan sonuç bölümünde ise ekonometrik analizin sonuçları doğrultusunda eğitim ile ekonomik büyüme arasındaki ilişki değerlendirilip, politika yapıcılara önerilerde bulunulmuştur.

\section{Literatür Taraması}

İktisat literatüründe ekonomik büyüme ve eğitim arasındaki ilişkiyi inceleyen teorik ve ampirik çalışmalar yoğun ilgi çekmektedir. Eğitimin ekonomik büyümeyi belirleyen temel değişkenlerden biri olduğu literatürde kabul görmektedir. Bu bağlamda eğitim ile ekonomik büyüme ilişkisini tespit etmeye yönelik teorik ve ampirik düzeyde yapılmış bazı araştırmalar aşağıda belirtilmiştir.

Barro (1991), 98 ülke için 1960-1985 dönemi verilerini kullanarak, kişi başına düşen reel GSYİH (Gayri Safi Yurtiçi Hasıla) büyüme oranı ile ilköğretime ve ortaöğretime kayıt oranı arasındaki ilişkiyi panel veri yöntemini uygulayarak analiz etmiştir. Çalışmaya göre kişi başına düşen reel GSYİH ile ilköğretime kayıt oranı arasında benzer bir ilişki bulunmaktadır.

Levine ve Renelt (1992), 1960-1989 dönemi için 119 ülkenin verilerini kullanarak, büyüme oranı ile GSYİH içerisindeki kamu eğitim harcamalarının payı ile ilk ve ortaöğretime katılım oranı arasındaki ilişkiyi analiz etmişlerdir. Levine ve Renelt'e göre ekonomik büyüme oranı ile kamu eğitim harcamalarının ulusal gelir içindeki oranı arasında güçlü bir ilişki vardır.

Zhang ve Casagrande (1998), 69 ülke için 1970-1985 dönemine ait veriler ile yapmış oldukları panel veri analizinde eğitime sağlanan sübvansiyonların ekonomik büyüme üzerinde pozitif etkisinin olduğu sonucuna ulaşmışlardır. 
Lin (2003), çalışmasında Tayvan için 1965-2000 dönemine ilişkin olarak reel sermaye stoku, reel GSYİH ve beşeri sermaye göstergesi olarak çalıştırılan işgücü başına düşen eğitim senelerinin ortalamasını kullanarak yapmış olduğu panel veri analizine göre eğitim ve ekonomik büyüme arasında pozitif yönlü bir ilişki vardır.

Self ve Grabowski (2003), çalışmalarında Japonya'da 1888-1940 ve 1947-1989 olmak üzere iki ayrı dönemi incelemişlerdir. Kişi başı GSYİH, ilköğretim, ortaöğretim, yükseköğretim ve mesleki eğitimde ortalama eğitim yılı değişkenlerini kullanmışlardır. Yapılan vektör hata düzeltme modeli analizi sonucunda iktisadi büyüme ile ilköğretim, ortaöğretim ve yükseköğretim arasında nedensellik olduğu tespit edilmiştir. Mesleki eğitimin ise ekonomik büyümeyi dolaylı etkilediği sonucuna ulaşmışlardır.

Musila ve Belassi (2004), Uganda için 1965-1999 dönemi için yapmış oldukları çalışmalarında devletin vatandaşları için yaptığı eğitim harcamaları ile reel GSYİH arasındaki ilişkiyi incelemişlerdir. Çalışma sonucunda işgücü başına düşen eğitim harcamalarının artması hem uzun hem de kısa dönemde ekonomik büyümeyi pozitif olarak etkilemektedir.

Self ve Grabowski (2004), 1966-1996 döneminde Hindistan'1 inceledikleri çalışmalarında, kişi başı reel GSYİH, ilköğretim, ortaöğretim ve yükseköğretim seviyelerinde kaydolma oranlarının yanında, kadınların ve erkeklerin ayrı ayrı eğitim seviyelerinin (ilköğretim, ortaöğretim ve yükseköğretim) datalarını kullanmışlardır. Yapılan Granger nedensellik testine göre ilk, orta ve yüksek düzeydeki kadın eğitimi ekonomik büyümeyi olumlu etkilemektedir. Erkeklerde ise yalnızca ilköğretim seviyesindeki eğitimin büyüme üzerinde nedensel bir etkisinin olduğu saptanmıştır.

Loening (2005), çalışmasında 1951-2002 dönemi verilerini kullanarak Guatemala için analiz yapmıştır. Çalışmada ilk ve ortaokul eğitimine kayıt oranı ile GSYİH değişkenleri kullanılmıştır. Analiz sonucunda beşeri sermayenin uzun vadeli büyüme üzerinde oldukça önemli ve olumlu bir etkisinin olduğu görülmüştür. Öyle ki beşeri sermaye değişkenleri üretim artışının \%50'sinden fazlasını açıklamaktadır. Ayrıca ortaokul eğitiminin büyümenin baskın belirleyicisi olduğu sonucuna ulaşılmıştır.

Brempong, Paddison ve Mitiku (2006), çalışmalarında 1960-2000 döneminde Afrika ülkelerinde yüksek eğitimin ekonomik büyüme üzerindeki etkisini araştırmışlardır. Yapılan dinamik panel veri analizine göre kişi başına reel GSYİH büyüme oranı üzerinde yüksek eğitim düzeyi de dâhil tüm eğitim seviyelerinin pozitif ve istatistiki olarak anlamlı etkiye sahip olduğu neticesine varılmıştır.

Afşar (2009), Türkiye'de eğitime yapılan yatırımlar ile ekonomik büyüme arasındaki ilişkiyi tespit etmek amacıyla, 1963-2005 dönemi verilerini kullandığ çalışmasında Granger nedensellik analizi yapmıştır. Afşar'a göre Türkiye'de 
eğitim yatırımları ve ekonomik büyüme arasında tek taraflı bir nedensellik vardır. Türkiye'deki eğitim yatırımları ile ekonomik büyüme arasındaki nedenselliğin yönü eğitim yatırımlarından ekonomik büyümeye doğrudur.

Telatar ve Terzi (2010), 1968-2006 dönemini kapsayan çalışmalarında Türkiye ekonomisinde nüfus, eğitim ve iktisadi büyüme arasındaki ilişkileri araştırmak amacıyla Granger nedensellik testi ve VAR analizi yapmışlardır. Analiz sonucunda iktisadi büyümeden yükseköğretim mezunları yönünde pozitif, nüfus yönünde ise negatif bir nedensellik ilişkisi tespit edilmiştir. Bunun yanında meslek lisesi mezunlarından iktisadi büyüme yönünde pozitif bir nedensellik olduğu anlaşılmıştır.

Çalışkan vd. (2013), Türkiye'de 1923-2011 döneminde eğitimin iktisadi büyümeye etkisini ortaya koyabilmek için yapmış oldukları ekonometrik analizde özellikle lise ve yükseköğretim başta olmak üzere eğitime daha çok kaynak ayrılmasının Türkiye'nin ekonomik gelişimine önemli ölçüde katkısının olacağı sonucuna ulaşmışlardır.

Akçacı (2013), çalışmasında, ekonomik büyüme ile eğitime yapılan harcamalar arasındaki ilişkiyi araştırmıştır. 1998Q1-2012Q3 dönemi için yapılan TodaYamamoto nedensellik testinin sonucuna göre eğitim yatırımlarından ekonomik büyüme yönünde tek taraflı bir nedenselliğin olduğu tespit edilmiştir.

Pamuk ve Bektaş (2014), çalışmalarında 1998:01-2013:02 döneminde Türkiye'de eğitim harcamalarının iktisadi büyüme üzerindeki etkisini araştırmışlardır. $\mathrm{Bu}$ amaç doğrultusunda yapmış oldukları analizler sonucunda eğitim yatırımları ile iktisadi büyüme arasında eşbütünleşme ilişkisinin olmadığı sonucuna ulaşmışlardır. Ancak yapmış oldukları Granger nedensellik testi doğrultusunda Türkiye'deki eğitim harcamaları ile iktisadi büyüme arasında tek yönlü nedensellik ilişkisinin olduğunu görülmüştür.

Yardımcıoğlu, Gürdal ve Altundemir (2014) çalışmalarında 1980-2008 dönemi için 25 OECD (The Organisation for Economic Co-operation and Development Ekonomik Kalkınma ve İşbirliği Örgütü) ülkesinde iktisadi büyüme ile eğitim arasındaki uzun dönemli ilişkiyi analiz etmişlerdir. Yapılan analiz sonucunda eğitim yatırımları ile iktisadi büyüme arasında uzun dönemde anlamlı ve çift taraflı ilişkinin varlığı anlaşılmıştır.

Yenisu (2018), çalışmasında Türkiye için 1960-2013 yıllık verilerini kullanarak, iktisadi büyüme ile eğitim düzeyleri arasındaki ilişkiyi analiz etmiştir. Analiz neticesinde uzun dönemde GSYİH ile ilköğretim, meslek lisesi ve üniversite öğrenci sayısı arasında bir ilişki olduğu bulunmuştur. Kısa dönemde ise; ilköğretim, lise ve üniversite öğrenci sayısından GSYİH yönünde, tek taraflı Granger nedensellik olduğu sonucuna ulaşılmıştır. 
Karış (2019), çalışmasında, Türkiye ekonomisi için 2003:Q1-2018:Q2 döneminde ekonomik büyüme ile eğitim harcamaları arasında nedensellik ve eşbütünleşme ilişkisini incelemiştir. Eşbütünleşme analizi sonucunda ekonomik büyüme ile eğitim harcamaları arasında eşbütünleşme ilişkisinin olduğu anlaşılmış, nedensellik analizine göre ise kısa ve uzun dönemde ekonomik büyümenin eğitim harcamalarının nedeni olmadığı sonucuna ulaşılmıştır. Ayrıca, sadece uzun dönemde eğitim harcamalarının ekonomik büyümenin nedeni olduğu tespit edilmiştir.

\section{Veri Seti ve Kaynakları}

Çalışmada 27 Avrupa Birliği (AB) ülkesine ait veriler kullanılmıştır. Çalışmanın amacı eğitimin ekonomik büyüme üzerindeki etkisini $\mathrm{AB}$ ülkeleri kapsamında analiz etmektir. Çalışmada verileri kullanılan AB ülkeleri; Almanya, Avusturya, Belçika, Bulgaristan, Çek Cumhuriyeti, Danimarka, Estonya, Finlandiya, Fransa, Güney Kıbrıs Rum Yönetimi, Hırvatistan, Hollanda, İrlanda, İspanya, İsveç, İtalya, Letonya, Litvanya, Lüksemburg, Macaristan, Malta, Polonya, Portekiz, Romanya, Slovakya, Slovenya ve Yunanistan'dır. Çalışmada kullanılan veriler 2002-2018 dönemini kapsamaktadır. Çalışmada yıllık veriler kullanılmıştır. AB ülkelerine ait GSYİH verisi Dünya Bankası'ndan ve ilköğretim, ortaöğretim ve yükseköğretim diplomasına sahip olan işgücü verileri Eurostat veri kaynağından alınmıştır.

\section{Yöntem ve Model}

Panel veri analiz yöntemi; ülkeler, firmalar, hanehalkları gibi kesit gözlemlerinin belirli bir dönemde bir araya gelmesidir. Bu yöntem; ülkelerin verilerini karşılıklı kullanarak büyümenin yakınsaması, inovasyon, uluslararası Ar-Ge yayılımı ve satınalma gücü paritesi gibi alanlarda çoğunlukla kullanılmaktadır (Hsiao, 2003, s.3; Baltagi, 2005, s. 237).

Ayrıca ülke örneğinin fazla olması, verilerde sıkıntı ve zaman aralığının geniş olması problemlerini ortadan kaldırabilmesi sebebiyle bu yöntem kullanışlı duruma gelmektedir (Baltagi, 2005, s. 237).

Panel veri analizinin dengesiz ve dengeli olmak üzere iki tane türü vardır. Dengeli analizde verilerin tüm kesitlerde eşit uzunluğa sahip zaman serisi kapsamas1 gerekirken, dengesiz panel veride, zaman serisinin uzunluğunun tüm kesitlerde değişiklik göstermesi gerekmektedir (Uncu, 2009, s. 30). Panel veri regresyonu; eğim katsayısı, sabit katsayı, hata terimi varsayımlarına dayanarak değişik şekillerde tahmin edilebilmektedir (Gujarati, 2006).

Panel veri modelleri; sabit etkiler ve rassal etkiler modeli olarak ayrılmaktadır. Birimlerin rassal olarak seçildiği rassal etkiler modelinde birimler arasındaki farklılıklar da rassal olmakta ve sabit etkiler modelinde görülen serbestlik derecesi 
sorunu oluşmamaktadır. Genel bir panel veri modeli şu şekildedir (Baldemir ve Keskiner, 2004, s. 47-48):

$y_{i t}=\beta_{1 i t}+\beta_{2 i t} X_{2 i t}+\beta_{3 i t} X_{3 i t}+e_{i t} \quad i=1,2, \ldots, n$ ve $t=1,2, \ldots \ldots$

$\beta_{1 \mathrm{it}}=\beta_{1} \quad \beta_{2 \mathrm{it}}=\beta_{2} \quad \beta_{3 \mathrm{it}}=\beta_{3}$ olduğu varsayılmaktadır. Bu modelde tek değişen sabit parametredir. Sabit terimdeki söz konusu farklılık kesite göre olup, hem zaman hem de kesiti değerlendirildiğinde model şu şekilde yazılmaktadır:

$\mathrm{y}_{\mathrm{i}}=\mathrm{x}_{1} \beta_{1 \mathrm{j}}+\mathrm{X}_{\mathrm{N}} \beta_{\mathrm{s}}+\mathrm{e}$

Rassal etkiler modeli ise örnekleme sürecinin sonucu olup bu süreç aşağıdaki şekilde işlemektedir (Gujarati, 2006):

$Y_{i t}=\beta_{1 i}+\beta_{2} X_{2 i t}+\beta_{3} X_{3 i t}+u_{i t}$

$\beta_{11}$ 'yi sabit değil de, rassal değişken şeklinde modele katıldığında, model şu şekilde yazılmaktadır:

$$
\begin{aligned}
& \beta_{1 \mathrm{i}}=\beta_{1}+\varepsilon_{\mathrm{i}} \quad \mathrm{i}: 1,2, \ldots, \mathrm{N} \\
& Y_{i t}=\beta_{1}+\beta_{2} X_{2 i t}+\beta_{3} X_{3 i t}+\varepsilon_{i t}+u_{i t} \\
& Y_{i t}=\beta_{1}+\beta_{2} X_{2 i t}+\beta_{3} X_{3 i t}+w_{i t}
\end{aligned}
$$

Burada $\quad w_{i t}=\varepsilon_{i t}+u_{i t}$ ' dir. Ayrıca $u_{i t}$, yatay kesit ile zaman serisinin birleşmesi nedeniyle oluşan spesifik hata terimiyken, $\varepsilon_{i t}$ ise yatay kesite özgü hata bileşenini temsil etmektedir. $w_{i t}$, iki bileşenden oluşan hata bileşenidir.

Panel veri analizlerinde rassal etkiler ya da sabit etkiler modelinin seçilmesinde verilerin önemli rolü vardır. Rassal etkiler modelinin en büyük dezavantajı, açıklayıcı değişkenler ile spesifik etkiler arasında herhangi bir korelasyon olmadığı varsayımından kaynaklanmaktadır. Sabit etkiler modelinin dezavantajı ise serbestlik derecesinden kaynaklanmaktadır (Yalçın, 2005, s. 47). Ayrıca hangi modelin seçileceğine karar verilirken Hausman testi de kullanılmaktadır. Bu test yapılarak $\mathrm{X}$ açıklayıcı değişkenler ile yatay kesite özgü etkiler $\varepsilon_{\text {it }}$ arasındaki korelasyona bakılmaktadır. Hausman testine göre spesifik etki rassal varsay1lmaktadir. Modelin hipotezleri: $\mathrm{H}_{0}=\mathrm{E}\left(\varepsilon_{\mathrm{it}} \backslash \mathrm{X}_{\mathrm{it}}\right)=0$ ise korelasyon yoktur. Ayrıca zaman serisi ve kesit verisi etkileri rassaldır. $H_{1}=E\left(\varepsilon_{i t} \backslash X_{i t}\right) \neq 0$ ise korelasyon vardır. Zaman serisi ve kesit verisi etkileri sabit olup; burada eğer sıfır hipotezi kabul edilirse rassal etkiler, reddedilir ise sabit etkiler modeli tercih edilmektedir (Park, 2010, s. 2). 
Seçilen ülke örnekleminin fazla olması nedeniyle çalışmada panel veri yöntemi seçilmiştir. Panel veri yöntemi ile ilgili literatürde verilen bilgiler de çalışmada bu yöntemin kullanılmasını destekler niteliktedir.

Analizde, 2002-2018 döneminde ekonomik büyüme ve eğitim arasındaki ilişkiyi tespit etmek için aşağıdaki model oluşturulmuştur.

$f g_{i t}=\alpha+\beta_{1} f i_{i t}+\beta_{2} f o_{i t}+\beta_{3} f y_{i t}+\varepsilon_{i t}+u_{i t}$

Modelde kullanılan değişkenler şunlardır:

fg: Ekonomik büyüme,

fi: İlköğretim diplomasına sahip işgücü,

fo: Ortaöğretim diplomasına sahip işgücü,

fy: Yükseköğretim diplomasına sahip işgücü.

\section{Ekonometrik Bulgular}

Çalışmada panel veri analizi 27 AB ülkesini (Almanya, Avusturya, Belçika, Bulgaristan, Çek Cumhuriyeti, Danimarka, Estonya, Finlandiya, Fransa, Güney Kıbrıs Rum Yönetimi, Hırvatistan, Hollanda, İrlanda, İspanya, İsveç, İtalya, Letonya, Litvanya, Lüksemburg, Macaristan, Malta, Polonya, Portekiz, Romanya, Slovakya, Slovenya ve Yunanistan) kapsamaktadır.

Çalışmada bağımlı değişken olan "fg" ekonomik büyümeyi temsil etmektedir. Bağımsız değişkenlerden "fi”" ilköğretim diplomasına sahip olan işgücünü ifade ederken, "fo" değişkeni ise ortaöğretim diplomasına sahip olan işgücünü göstermektedir. Ayrıca "fy", değişkeni yükseköğretim diplomasına sahip olan işgücünü temsil etmektedir. 2002-2018 yıllarını kapsayan çalışmada fg, fi, fo ve fy değişkenlerine ait ikincil veriler Eurostat ve Dünya Bankası veri tabanlarından alınmıştır. Ayrıca panel veri analizi bağımsız değişkenlerin ve bağımlı değişkenin birincil farklı değerleri ile yapılmıştır. 
Tablo 1: Birim Kök Testlerinin Sonuçları

\begin{tabular}{|l|c|c|c|c|c|c|}
\hline \multirow{2}{*}{ Destler } & \multicolumn{2}{|c|}{ Harris-Tzavalis } & \multicolumn{2}{c|}{ Breitung } & \multicolumn{2}{c|}{ Im-Pesaran-Shin } \\
\cline { 2 - 7 } & Katsayı & $\begin{array}{c}\text { P- } \\
\text { Değeri }\end{array}$ & Katsay1 & $\begin{array}{c}\text { P- } \\
\text { Değeri }\end{array}$ & Katsay1 & P-Değeri \\
\hline lng & 0.7469 & 0.9989 & 1.8280 & 0.9662 & -1.1120 & 0.1331 \\
\hline fg & $\begin{array}{c}0.5128 \\
*\end{array}$ & 0.0735 & $\begin{array}{c}-5.5151 \\
* *\end{array}$ & $<0.0001$ & $\begin{array}{c}-5.4043 \\
* *\end{array}$ & $<0.0001$ \\
\hline $\operatorname{lni}$ & 0.6707 & 0.9211 & 0.3506 & 0.6370 & -1.9326 & 0.0266 \\
\hline fi & $\begin{array}{c}0.1345 \\
* *\end{array}$ & $<0.0001$ & $\begin{array}{c}-6.8160 \\
* *\end{array}$ & $<0.0001$ & $\begin{array}{c}-7.4606 \\
* *\end{array}$ & $<0.0001$ \\
\hline $\operatorname{lno}$ & 0.6620 & 0.8897 & 0.9273 & 0.8231 & -1.8622 & 0.0313 \\
\hline fo & $\begin{array}{c}* .3465 \\
* *\end{array}$ & $<0.0001$ & $\begin{array}{c}-5.6901 \\
* *\end{array}$ & 0.0000 & $\begin{array}{c}-7.3795 \\
* *\end{array}$ & $<0.0001$ \\
\hline $\operatorname{lng}$ & 0.5100 & 0.0199 & -0.8566 & 0.1958 & -4.7829 & $<0.0001$ \\
\hline fy & $\begin{array}{c}-0.0661 \\
* *\end{array}$ & $<0.0001$ & $\begin{array}{c}* .2334 \\
* *\end{array}$ & $<0.0001$ & $\begin{array}{c}-9.9266 \\
* *\end{array}$ & $<0.0001$ \\
\hline
\end{tabular}

**: İstatistiksel olarak \%5 düzeyinde anlamlıdır.

*: İstatistiksel olarak \%10 düzeyinde anlamlıdır.

Çalışmada yapılan birim kök testleri Breitung, Im-Pesaran-Shin ve HarrisTzavalis'tir. lng bağımlı değiş̧keni ile bağımsız değişkenler lni, lno ve lny'nin bütün birim kök testlerinde düzeyde durağan olmamaları nedeniyle, bağımlı değişken lng ve bağımsız değişkenler lni, lno ve lny'nin birincil farkları alınarak, elde edilen fg, fi, fo ve fy değişkenlerinin yapılan birim kök testleri sonuçlarına göre fg, fi, fo, fy değişkenleri \%5 anlamlılık düzeyinde durağandır (Tablo 1). Ayrıca analiz için sabit etkiler modelinin daha uygun olduğu Hausman testi yapılarak tespit edilmiştir. Çünkü yapılan bu test neticesinde "Prob>chi2 = 0.0000 " sonucu elde edilmiştir.

Tablo 2: Hausman Testi Sonucu

\begin{tabular}{|l|c|}
\hline Bağımlı Değişken & fg \\
\hline Prob $>$ chi2 & $<0.0001$ \\
\hline Sonuç & Sabit \\
\hline
\end{tabular}

Hausman testi, panel veri analizlerinde sabit etkiler ya da rassal etkiler modellerinden birinin seçiminde kullanılmaktadır. Ayrıca Hausman testi bağımsız değişkenler ve bireysel etkiler arasında ilişki olup olmadığını tespit etmek için de kullanılmaktadır. Hausman testinde $\mathrm{H}_{0}$ hipotezi (rassal etki hâkim) onaylanmazsa sabit etkiler, onaylanırsa rassal etkiler modeli tercih edilmektedir (Clark ve Linzer, 2012, s. 11). Tablo 2'de Hausman testi p-değeri “0,000” olup, p<0.05 olduğu için $\mathrm{H}_{0}$ (rassal etki hâkim) hipotezi reddedilerek, sabit etkiler modeli tercih edilmiştir. 
Tablo 3: Diagnostik Testlerinin Sonuçları

\begin{tabular}{||l|l|l|l|l|l||}
\hline \multicolumn{2}{|c|}{ Heteroskedasite } & \multicolumn{2}{c|}{ Otokorelasyon } & \multicolumn{2}{c|}{ Birimlerarası Korelasyon } \\
\hline \multirow{2}{*}{ Prob>chi2 } & $<0.001$ & $\begin{array}{l}\text { Bhargava et } \\
\text { al. Durbin- } \\
\text { Watson }\end{array}$ & 1.65615 & $\operatorname{Pr}$ & $<0.0001$ \\
\cline { 3 - 6 } & $\begin{array}{l}\text { Baltagi-Wu } \\
\text { LBI }\end{array}$ & 1.7206758 & $\begin{array}{l}\text { Otokorelasyon } \\
\text { Var }\end{array}$ & Sonuç & $\begin{array}{l}\text { Birimleraras1 } \\
\text { Korelasyon } \\
\text { Var }\end{array}$ \\
\hline Sonuç & $\begin{array}{l}\text { Heteroskedasite } \\
\text { Var }\end{array}$ & Sonuç & & &
\end{tabular}

Analizin güvenirliliğini tespit etmek amacıyla heteroskedasite, otokorelasyon ve birimlerarası korelasyon testleri yapılarak, heteroskedasitenin, otokorelasyonun ve birimlerarası korelasyonun varlığı tespit edilmiştir. Çünkü heteroskedasiteyi belirlemek için uygulanan değiștirilmiş wald testinin prob>chi2 sonucu " 0.000 " çıkarak, heteroskedasitenin varlığı anlaşılmıştır. Ayrıca otokorelasyonu tespit etmek amacıyla uygulanan testlerin sonuçlarının kritik değer 2'den küçük olması otokorelasyonun olduğunu göstermektedir. Bununla birlikte birimlerarası korelasyonun olup olmadığını anlamak için uygulanan Breusch Pagan testinin pr değerinin kritik değer 0.05 'ten küçük olması ile birimlerarası korelasyon sorunu tespit edilmiştir (Tablo 3). Bu problemleri gidermek amaciyla robust panel veri analizi yapılmıştır.

Tablo 4: Panel Veri Testi Sonuçları

\begin{tabular}{|c|c|c|c|c|}
\hline \multicolumn{5}{|c|}{ Bağımlı değişken fg } \\
\hline Değişkenler & Coef. & $\mathrm{P}>|\mathrm{z}|$ & {$[95 \% \mathrm{Co}$} & Interval] \\
\hline fi & $\begin{array}{c}0.1705741 \\
* *\end{array}$ & $<0.001$ & 0.161836 & 0.17931 \\
\hline fo & $\begin{array}{c}0.2806356 \\
* *\end{array}$ & $<0.001$ & 0.25504 & 0.306229 \\
\hline fy & $\begin{array}{c}0.1422064 \\
* *\end{array}$ & $<0.001$ & 0.122600 & 0.161812 \\
\hline cons & 0.0194951 & $<0.001$ & 0.017250 & 0.021740 \\
\hline
\end{tabular}

**: İstatistiksel olarak \%5 seviyesinde anlamlıdır.

fi bağımsız değişkeni, fg bağımlı değişkenini öngörüldüğü gibi pozitif yönde etkilemektedir. Çünkü fi \%1 arttı̆̆ında, fg \%0,17 artmaktadır. Bununla birlikte fo bağımsız değişkeni, fg bağımlı değişkenini pozitif yönde etkilemektedir. Sebebi fo'da \%1'lik bir artış olduğunda, fg'yi \%0,28 artırmaktadır. Ayrıca bağımsız değişken fy, bağımlı değişken fg'yi pozitif olarak etkilemektedir. Çünkü fy'de $\% 1$ 'lik artış olduğunda, fg \%0,14 artmaktadır (Tablo 4). 


\section{Sonuç}

Gelişmiş ülke ekonomilerinin en büyük avantajlarından biri de iyi eğitilmiş, nitelikli işgücüne sahip olmalarıdır. Bir ülkede eğitim seviyesinin yükselmesi işgücünün verimliliğini arttırmakta, bu da ekonomik büyüme üzerinde olumlu etki yaratmaktadır. Ülkedeki eğitim düzeyi, ülke ekonomisinin kalkınma sürecine dinamizm katmaktadır.

Bu çalışmada, eğitim ile ekonomik büyüme arasındaki ilişkiyi tespit edebilmek amacıyla 2002-2018 dönemini kapsayan y1llık verilerle AB ülkeleri için analiz yapılmıştır. AB ülkeleri ile yapılan panel veri analizi sonucuna göre ilköğretim, ortaöğretim ve yükseköğretim diplomasına sahip olan işgücünün ekonomik büyümeyi pozitif yönde etkilediği tespit edilmiştir. Farklı eğitim düzeyinde çalışan işgücü sayısı ile ekonomik büyüme arasındaki ilişkiyi belirtmek için yapılan analiz sonucunda elde edilen sonuç literatürdeki ekonomik büyüme ile eğitim arasında pozitif yönlü bir ilişki bulunduğunu ifade eden genel kanıyı desteklemektedir.

Ortaöğretim diplomasına sahip olan işgücünün ekonomik büyümeyi olumlu yönde etkilemesi aslında mesleki eğitim veren okulları da kapsadığı için mesleki açıdan teknik bilgi ve beceriye sahip olan kişilerin iş hayatında ekonomik büyümeye katkı sağladıkları da anlaşılmaktadır. Dolayısıyla mesleki eğitimin öneminin farkına varılarak kalite ve etkinliğinin arttırılması önem arz etmektedir. Bu sonuç da literatürdeki mesleki eğitimin ekonomik büyüme üzerinde etkili olduğunu savunan görüşleri destekler niteliktedir.

Çalışma, AB ülkelerinde eğitimin ekonomik büyümeyi arttırdığını göstermektedir. $\mathrm{Bu}$ bağlamda çalışmada elde edilen bulgular neticesinde politika yapıcılara sürdürülebilir iktisadi büyümeyi yakalamaları için eğitime daha çok kaynak ayırmaları önerilmektedir. 


\section{Kaynakça}

Afşar, M. (2009). Türkiye'de eğitim yatırımları ve ekonomik büyüme ilişkisi. Anadolu Üniversitesi Sosyal Bilimler Dergisi, 9(1), 85-98.

Akçacı, T. (2013). Eğitim harcamalarının iktisadi büyümeye etkisi. $K A U$ İ̈BF Dergisi, 4(5), 65-79.

Baldemir, E. ve Keskiner, A. (2004). Devalüasyon, para, reel gelir değişkenlerinin dış ticaret üzerine etkisinin panel data yöntemiyle Türkiye için incelenmesi. Dokuz Eylül Üniversitesi Sosyal Bilimler Enstitüsü Dergisi, $6(4)$.

Baltagi, B. H. (2005). Econometric analysis of panel data. West Sussex: John Wiley \& Sons Ltd.

Barro, R. J. (1991). Economic growth in a cross section of countries. The Quar terly Journal of Economics, 106(2), 407-443.

Becker, G. (1964). Human capital: A theoretical and empirical analysis with special reference to education. Columbia University Press, New York.

Brempong, K. G., Paddison, O. ve Mitiku, W. (2006). Higher education and economic growth in Africa. Journal of Development Studies, 42(3), 509529.

Clark, S.T. ve Linzer, D. A. (2012). Should I Use Fixed or Random Effects? http://polmeth.wustl.edu/media/Paper/ClarkLinzerREFEMar2012.pdf(Eri şim Tarihi: 14 Haziran 2020)

Çalışkan, Ş., Karabacak, M. ve Meçik, O. (2013). Türkiye'de eğitim-ekonomik büyüme ilişkisi: 1923-2011 (kantitatif bir yaklaşım). Yönetim Bilimleri Dergisi, 11(21), 29-48.

Denison, E. F. (1962). Education, economic growth, and gaps in information. Journal of Political Economy, 70(5), 124-128.

Gujarati, D. N. (2006). Temel ekonometri. (Ü. Şenesen ve G.G. Şenesen, Çev.). İstanbul: Literatür Yayıncilık.

Harbison, F. H. (1971). Human resources as the wealth of nations. American Philosophical Society, 115(6), 426-431.

Hsiao, C. (2003). Analysis of panel data. Cambridge: Cambridge University Press. 
Karış, Ç. (2019). Eğitim harcamaları ve ekonomik büyüme üzerine bir nedensellik analizi: Türkiye örneği. Bingöl Üniversitesi Sosyal Bilimler Enstitüsü Dergisi, 9(18), 1067-1088.

Levine, R. ve Renelt, D. (1992). A sensitivity analysis of cross-country growth regressions. The American Economic Review, 82(4), 942-963.

Lin, T. C. (2003). Education, technical progress, and economic growth: The case of Taiwan. Economics of Education Review, 22(2), 213-220.

Loening, J. L. (2005). Effects of primary, secondary and tertiary education on economic growth evidence from Guatemala. World Bank Policy Research Working Paper, Rapor No: WPS3610.

Lucas, R. E. (1988). On the mechanics of economic development. Journal of Monetary Economics, 22, 3-42.

Mankiw, N. G., Romer, D., Weil, D. N. (1992). A Contribution to the empirics of economic growth, The Quarterly Journal of Economics, 107(2), 407-437.

Musila, J.W. ve Belassi, W. (2004). The impact of education expenditures on economic growth in Uganda: Evidence from time series data. The Journal of Developing Areas, 38(1), 123-133.

Pamuk, M. ve Bektaş, H. (2014). Türkiye'de eğitim harcamaları ve ekonomik büyüme arasındaki ilişki: ARDL sınır testi yaklaşımı. Siyaset, Ekonomi ve Yönetim Araştırmaları Dergisi, 2(2), 77-90.

Park, H. M. (2010). Practical Guides to Panel Data Analysis. http://www.iuj.ac.jp /faculty/kucc625/writing/panel_guidelines.pdf (Erişim Tarihi: 07 Kasım 2019)

Romer, P. M. (1990). Endogenous technological change. Journal of Political Economy, 98(5), 71-102.

Schultz, T. (1961). Investment in human capital. The American Economic Review, 51(1), 1-17.

Self, S. ve Grabowski, R. (2003). Education and long-run development in Japan. Journal of Asian Economics, 14(4), 565-580.

Self, S. ve Grabowski, R. (2004). Does education at all levels cause growth? India, a case study. Economics of Education Review, 23(1), 47-55. 
Solow, R. (1956). A contribution to the theory of economic growth. The Quarterly Journal of Economics, 70(1), 65-94.

Telatar, O. M. ve Terzi, H. (2010). Nüfus ve eğitimin ekonomik büyümeye etkisi: Türkiye üzerine bir inceleme. Atatürk Üniversitesi İktisadi ve İdari Bilimler Fakültesi Dergisi, 24(2), 197-214.

Uncu, F. (2009). Doğrudan yabancı yatırımlarla ilgili panel veri araştırması (Yayımlanmamış yüksek lisans tezi). İnönü üniversitesi sosyal bilimler enstitüsü, Malatya.

Yalçın, E. (2005). İktisadi büyüme ve dış krediler: Ampirik bir çalışma (Yayımlanmamış uzmanlık tezi). Türkiye cumhuriyet merkez bankası dış ilişkiler genel müdürlügüu, Ankara.

Yardımcıoğlu, F., Gürdal, T. ve Altundemir, M. E. (2014). Eğitim ve ekonomik büyüme ilişkisi: OECD ülkelerine ilişkin panel eşbütünleşme analizi (1980-2008). Eğitim ve Bilim, 39(173), 1-12.

Yenisu, E. (2018). Türkiye'de eğitim düzeylerinin ekonomik büyümeye etkisi. Doğu Anadolu Sosyal Bilimlerde Eğilimler Dergisi, 2(1), 27-44.

Zhang, J. ve Casagrande, R. (1998). Fertility, growth and flat-rate taxation for education subsidies. Economics Letters, 60(2), 209-216. 


\section{The Impacts of Education on Economic Growth: Panel Data Analysis for EU Countries}

\section{Extended Abstract}

\section{Introduction}

The concept of human capital trace to classical economists such as Adam Smith, J. Stuart Mill and Alfred Marshall. In the 1960s, economists such as Schultz (1961), Denison (1962) and Becker (1964) developed the human capital theory, which was put forward formally for the first time, based on Smith's views. Denison (1962) revealed that the increase in the education level of the workforce increases economic growth as a result of the analysis. Harbison (1971) emphasized that education is a fundamental factor in economic growth.

Solow (1956) is important in terms of reveal the foundations of the concept of economic growth. According to the Solow model, economic growth is determined by more investment and labor force growth rate. Also, according to the model, technological development is an important factor affecting growth. Mankiw, Romer, and Weil (1992) emphasized that human capital has an important role in economic growth by adding the human capital variable to the Solow growth model. In addition, Romer (1990) indicated that human capital is one of the important determinants of economic growth.

Today it is accepted that education significantly affects economic growth. Studies conducted to understand the effect of education on economic growth in economic theory constitute a large literatüre. The study differs from other studies in terms of data used, year range analyzed and country samples. This difference constitutes the original value of the study. The aim of the study is to investigate the relationship between economic growth and education in the European Union (EU). In line with this purpose, the study primarily includes studies in the literature that investigate the relationship between economic growth and education at an empirical and theoretical level. In the next stages, after giving information about the data sources and the method, the relationship between education and economic growth was examined by applying panel data analysis in the context of the European Union country examples for the period 2002-2018. In conclusion, the relationship between education and economic growth is evaluated in line with the results of the econometric analysis, and recommendations have been made to policy makers.

\section{Method}

Data from 27 European Union (EU) countries were used in the study. The aim of the study is to analyze the impact of education on economic growth within the EU countries. EU countries whose data are used in the study; Germany, Austria, Belgium, Bulgaria, Czech Republic, Denmark, Estonia, Finland, France, Greek Cypriot Administration of Southern Cyprus, Croatia, Netherlands, Ireland, Spain, Sweden, Italy, Latvia, Lithuania, Luxembourg, Hungary, Malta, Poland, Portugal, Romania, Slovakia, Slovenia and Greece. The data used in the study cover the period 2002-2018. Annual data were used in the study. GDP data of EU countries are taken from the World Bank, and labor force data with primary, secondary and higher education diplomas are taken from Eurostat data source. Panel data method was chosen in the study due to the large sample size of the selected country. The information given in the literature about the panel data method also supports the use of this method in the study.

The dependent variable "fg" in the study represents economic growth. While "fi", one of the independent variables, expresses the workforce with a primary education diploma, the variable 
"fo" indicates the workforce with a secondary education diploma. In addition, "fy" variable represents the workforce with higher education diploma. Panel data analysis was performed with primary different values of independent variables and dependent variable.

\section{Results and Discussion}

Unit root tests performed in the study are Breitung, Im-Pesaran-Shin and Harris-Tzavalis. Since the dependent variable lng and the independent variables lni, lno, and lny are not stationary at the level in all unit root tests, the primary differences of the dependent variables lng and the independent variables lni, lno and lny are taken and the obtained variables fg, fi, fo and fy. According to the results of the unit root tests, variables fg, fi, fo, fy are stationary at 5\% significance level. In addition, it was determined that the fixed effects model was more suitable for analysis by using the Hausman test.

In order to determine the reliability of the analysis, heteroscedasticity, autocorrelation and interunit correlation tests were performed, and the existence of heteroscedasticity, autocorrelation and inter-unit correlation was determined. Robust panel data analysis has been performed in order to eliminate these problems.

The fi independent variable positively affects the fg dependent variable as predicted. Because when fi increases by $1 \%$, fg increases by $0.17 \%$. However, the fo independent variable positively affects the fg dependent variable. Because when there is a $1 \%$ increase in fo, it increases fg by $0.28 \%$. In addition, the independent variable fy positively affects the dependent variable fg. Because when there is a $1 \%$ increase in fy, fg increases by $0.14 \%$.

\section{Conclusion}

According to the results of the panel data analysis conducted with EU countries, it was determined that the workforce with primary, secondary and higher education diplomas positively affected economic growth. The result obtained in the analysis made to indicate the relationship between the number of workforce working at different educational levels and economic growth supports the general opinion in the literature that there is a positive relationship between economic growth and education. The study indicates that education increases economic growth in EU countries. In this context, as a result of the findings of the study, it is recommended that policy makers allocate more resources for education in order to achieve sustainable economic growth. 